\title{
Mechanism and kinetics of early transition metal hydrides, oxides, and chlorides to enhance hydrogen release and uptake properties of $\mathrm{MgH}_{2}$
}

\author{
Dmytro Korablov, ${ }^{1}$ Thomas K. Nielsen, ${ }^{1}$ Flemming Besenbacher, ${ }^{2}$ and Torben R. Jensen ${ }^{1, a)}$ \\ ${ }^{I}$ Department of Chemistry, Center for Materials Crystallography (CMC), Interdisciplinary Nanoscience Center (iNANO), Aarhus \\ University, Langelandsgade 140, DK-8000 Aarhus C, Denmark \\ ${ }^{2}$ Interdisciplinary Nanoscience Center (iNANO) and Department of Physics and Astronomy, Aarhus University, Ny Munkegade \\ 120, DK-8000 Aarhus C, Denmark
}

(Received 30 September 2014; accepted 5 January 2015)

\begin{abstract}
Selected hydrides $\left(\mathrm{TiH}_{2}, \mathrm{ZrH}_{2}\right)$, chlorides $\left(\mathrm{VCl}_{3}, \mathrm{ScCl}_{3}\right)$ or oxides $\left(\mathrm{V}_{2} \mathrm{O}_{5}\right)$ utilized as additives facilitating hydrogen release and uptake for magnesium hydride were investigated using mechanochemical treatment and in-situ synchrotron radiation powder X-ray diffraction studies. The fastest hydrogen desorption and absorption kinetics for $\mathrm{MgH}_{2}$ was observed for a sample with $5 \mathrm{~mol} \%$ $\mathrm{V}_{2} \mathrm{O}_{5}$ at $320{ }^{\circ} \mathrm{C}$. Additional activation of the system ( 2 cycles, vacuum $/ p\left(\mathrm{H}_{2}\right) \sim 150 \mathrm{bar}, 450{ }^{\circ} \mathrm{C}$ ) leads to significant improvement of the kinetics even at lower temperatures, $270{ }^{\circ} \mathrm{C}$. The observed prolific effect is achieved through the full reduction of vanadium oxides and formation of an efficient vanadium catalyst as nanoparticles and possibly interfacial effects in the $\mathrm{MgO} / \mathrm{Mg} / \mathrm{MgH}_{2} / \mathrm{V}$ system introduced during cycling hydrogen release and uptake in hydrogen/dynamic vacuum at $450{ }^{\circ} \mathrm{C}$. Nanostructuring as well as hydrogen permeability via vanadium nanoparticles may improve kinetics and reduce the apparent activation energy for hydrogen release. Thus, the enhancement of hydrogen release/uptake in the $\mathrm{MgH}_{2}$ owe to "in situ" formation of vanadium nanoparticles by reduction of $\mathrm{V}_{2} \mathrm{O}_{5}$. (C) 2015 International Centre for Diffraction Data. [doi:10.1017/S0885715615000056]
\end{abstract}

Key words: hydrogen storage, magnesium hydride, vanadium pentoxide, ball milling, in situ synchrotron powder X-ray diffraction

\section{INTRODUCTION}

Currently, magnesium hydride is the subject of many scientific studies as a promising material for hydrogen storage. Obstacles to its widespread use are the high decomposition temperature $\left(\sim 300^{\circ} \mathrm{C}\right)$ and the slow kinetics of hydrogen absorption-desorption. Traditionally, the solution to these problems is found in nanostructuring that can be achieved, for example, by mechano-chemical treatment (Huot et al., 1999; Paskevicius et al., 2010), use of effective catalysts (Schimmel et al., 2005; Varin et al., 2011) or by introducing of additives that alter the thermodynamic properties of the system (Jin et al., 2007a; Cuevas et al., 2012). Nanosized metals may have lower melting point or spontaneous alloying as compared with their bulk form (Hirokazu and Kitagawa, 2012). In addition, nanostructuring by mechano-chemical treatment often improve kinetics but may also lead to surface contamination with material from the milling equipment (Pasquini et al., 2011; Huot et al., 2013). A remaining challenge is the stabilization of magnesium nanoparticles and preventing agglomeration, sintering, oxidation, and potential side reactions leading to rapid deterioration of material properties upon cycling (Sato and Ishikawa, 2012). Nanoconfinement of magnesium has been investigated and was shown to increase the kinetics for hydrogen release and uptake and

\footnotetext{
a) Author to whom correspondence should be addressed. Electronic mail: trj@chem.au.dk
}

may also provide improved thermodynamic properties (Nielsen et al., 2009, 2011; Paskevicius et al., 2010; Vajo, 2011).

A wide range of different types of additives including metals, oxides, halides, and hydrides has been considered for possible prolific effects on hydrogen release and uptake. Nanonickel (n-Ni) is well established as efficient catalyst for the $\mathrm{Mg} / \mathrm{MgH}_{2}$ system, which acts via the intermediate $\mathrm{Mg}_{2} \mathrm{NiH}_{4}$ (Jensen et al., 2006; Varin et al., 2009, 2011; Pasquini et al., 2011; Callini et al., 2013). Other metals, e.g., $\mathrm{Al}, \mathrm{Ti}, \mathrm{Cu}, \mathrm{Pd}$ may have both a thermodynamic and kinetic effect by forming magnesium containing alloys (Andreasen et al., 2005, 2006; Callini et al., 2010). In particular, titanium is relevant because of low costs, lighter weight, and fast kinetics for hydrogen release and uptake for $\mathrm{Mg} / \mathrm{MgH}_{2}$. Moreover, magnesium does not form intermetallic compounds with $\mathrm{V}$ and $\mathrm{Nb}$ (Massalski, 1990). Therefore, both metals are considered as heterogeneous catalysts (Schimmel et al., 2005).

Transition metal oxides are also good catalysts for enhancement of hydrogen release and uptake e.g., $\mathrm{Nb}_{2} \mathrm{O}_{5}$ (Barkhordarian et al., 2006) and $\mathrm{V}_{2} \mathrm{O}_{5}$ (Oelerich et al., 2001a, 2001b; Jung et al., 2006). A drawback may be that some metal oxides have a tendency to reduce during cycling hydrogen release and uptake, which leads to the formation of inert magnesium oxide. The detailed mechanism for metal oxides prolific action may be complex and in some cases is not fully understood. An in situ synchrotron radiation powder X-ray diffraction (SR-PXD) investigation of $\mathrm{MgH}_{2}$ and $\mathrm{Nb}_{2} \mathrm{O}_{5}(8 \mathrm{~mol} \%)$ revealed reduction of $\mathrm{Nb}(\mathrm{V})$ and 
formation of $\mathrm{Mg}_{1-x} \mathrm{Nb}_{x} \mathrm{O}$, which may facilitate release and uptake of hydrogen (Nielsen and Jensen, 2012).

Transition metal halides have also been successfully utilized as additives for improving the kinetics of the absorption/desorption of hydrogen in $\mathrm{MgH}_{2}$, e.g., $\mathrm{VCl}_{3}$ and $\mathrm{TiCl}_{3}$ (Malka et al., 2010). Moreover, halides of $\mathrm{Fe}, \mathrm{Ni}$, and $\mathrm{Nb}$ have also shown attractive catalytic properties (Ivanov et al., 2003; Deledda et al., 2005; Bhat et al., 2006; Kim et al., 2008; Ma et al., 2009).

Transition metal oxides and halides may in some cases react with $\mathrm{MgH}_{2}$ or $\mathrm{Mg}$ and form other compounds. Currently, there is no clear picture of their mechanism of action and the active compound may not be known (Barkhordarian et al., 2006; Jin et al., 2007b). This has prompted the present investigation of binary early $d$-block hydrides, oxides, and chlorides used as additives for the $\mathrm{Mg} / \mathrm{MgH}_{2}$ system. We utilize in situ SR-PXD to provide a more detailed picture of mechanism for hydrogen release and uptake as well as identification of active compounds in the mixtures.

\section{EXPERIMENTAL}

\section{A. Sample preparation}

Mixtures of $\mathrm{MgH}_{2}$ (98\%, Alfa Aesar) with $5 \mathrm{~mol} \%$ of additive were ball milled under argon atmosphere using tungsten carbide (WC) hard alloy vial $(80 \mathrm{ml})$ and balls $(10 \mathrm{~mm}$ diameter) in a Fritsch Pulverisette P4 planetary mill. As additives, commercially available chemicals were used: vanadium pentoxide $\left(\mathrm{V}_{2} \mathrm{O}_{5}, 98+\%\right.$, Aldrich), titanium hydride $\left(\mathrm{TiH}_{2}, 98 \%\right.$, Aldrich), zirconium hydride $\left(\mathrm{ZrH}_{2}, 99 \%\right.$, Aldrich), vanadium chloride $\left(\mathrm{VCl}_{3}, 97 \%\right.$, Aldrich), and scandium chloride $\left(\mathrm{ScCl}_{3}\right.$, $99.9 \%$, Aldrich). The typical mass of each mixture constituted $3 \mathrm{~g}$ with $1: 41$ powder-to-ball weight ratio. The milling was performed in time intervals of $30 \mathrm{~min}$ at a rotation speed of $300 \mathrm{rpm}$ (Huot et al., 2013).

Experimental details regarding samples composition and preparation can be found in Table I. All handling and manipulation of the chemicals were carried out under argon atmosphere in an MBraun Unilab glove box with a recirculation gas purification system and gas/humidity sensors. Oxygen and water levels were kept well below $1 \mathrm{ppm}$ during all operations.

\section{B. In situ synchrotron radiation powder X-ray diffraction (SR-PXD)}

The detailed reaction mechanisms and kinetics of hydrogen release and uptake in $\mathrm{MgH}_{2}$ with different additives were studied by in situ SR-PXD experiments. Data were collected at beamline I711 at the synchrotron MAX II, in the research laboratory MAX-lab, Lund, Sweden using a Mar165 CCD

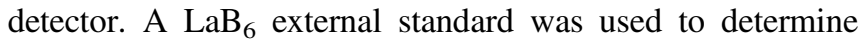
sample-detector distance, detector orientation, and the wavelength. The samples were mounted in sapphire single crystal tubes $\left(\mathrm{Al}_{2} \mathrm{O}_{3}\right.$, o.d. $1.09 \mathrm{~mm}$, i.d. $\left.0.79 \mathrm{~mm}\right)$ in an argon-filled glove box $\left(p\left(\mathrm{O}_{2}, \mathrm{H}_{2} \mathrm{O}\right)<1 \mathrm{ppm}\right)$. The sample holder was specially developed for the study of gas/solid reactions and hydrogen pressures were allowed up to $20 \mathrm{MPa}$ and temperatures from room temperature (RT) to $800{ }^{\circ} \mathrm{C}$ (Jensen et al., 2010). The selected wavelength was $0.94608 \AA$ and the $\mathrm{X}$-ray exposure time was $5 \mathrm{~s}$ per PXD pattern. Samples for investigation of mechanism and kinetics of hydrogen release and uptake were heated stepwise to fixed temperatures of 270 and $320^{\circ} \mathrm{C}\left(15^{\circ} \mathrm{C} \mathrm{min}-1\right)$ in a hydrogen pressure of 100-150 bar. The hydrogen pressure was reduced to $p\left(\mathrm{H}_{2}\right)$ $\sim 10^{-2}$ bar (dynamic vacuum) when the fixed temperature was reached and then again increased to $100-150$ bar when the sample was fully dehydrogenated (after 15 to $30 \mathrm{~min}$ ) measuring one full hydrogen release and uptake cycle at each temperature. Selected samples were additionally heated to $450{ }^{\circ} \mathrm{C}$ and two extra $\mathrm{H}_{2}$ desorption/absorption cycles were performed. Finally, the samples were cooled to $270{ }^{\circ} \mathrm{C}$ and one dehydrogenation was conducted.

All obtained raw images were transformed to twodimensional powder patterns using the FIT2D program (Hammersley et al., 1996), which was also used for calibration using measurements of the standard NIST $\mathrm{LaB}_{6}$ sample. Crystal structure refinements were performed using the Rietveld method implemented in the Fullprof program (Rodríguez-Carvajal, 1993). The backgrounds were described by linear interpolation between selected points, while pseudo-Voigt profile functions were used to fit the diffraction peaks. Sequential refinements provide the weight fractions for the compounds present in the sample as a function of time. The extracted normalized curves represent phase formation or decomposition curves as a function of time denoted $\alpha(t)$. These sigmoidal shaped curves can be used for evaluation of the activation process.

The decomposition curves for $\mathrm{MgH}_{2}$ can be fitted well with the equation of shrinking core model:

$$
1-(1-\alpha)^{1 / 2}=k t
$$

where $\alpha$ is the phase fraction at time $t$ and $k$ is the rate constant (Liang et al., 2000; Varin et al., 2009).

An apparent activation energy, $E_{\mathrm{A}}$, and a pre-factor, $A$, for the overall reaction can be calculated using Arrhenius law:

$$
k=A \exp \left(-E_{A} / R T\right)
$$

where $R$ is the gas constant and $T$ is the absolute temperature.

\begin{tabular}{|c|c|c|c|c|c|c|}
\hline \multicolumn{2}{|c|}{ Sample notation } & \multicolumn{2}{|c|}{$\begin{array}{l}\text { Composition } \\
\text { (mol\%) } \mathrm{MgH}_{2} \\
\text { additive }\end{array}$} & \multirow{2}{*}{$\begin{array}{c}\text { Ball milling } \\
\text { conditions time (min) } \\
\text { (interval, brake) }\end{array}$} & \multirow{2}{*}{$\begin{array}{c}\begin{array}{c}\text { Ball to powder } \\
\text { weight ratio }\end{array} \\
41: 1\end{array}$} & \multirow{2}{*}{$\begin{array}{c}\begin{array}{c}\text { Rotation speed } \\
\text { (rpm) }\end{array} \\
300\end{array}$} \\
\hline S1 & $\mathrm{MgH}_{2}+\mathrm{V}_{2} \mathrm{O}_{5}$ & 95 & 5 & & & \\
\hline $\mathrm{S} 2$ & $\mathrm{MgH}_{2}+\mathrm{ZrH}_{2}$ & 95 & 5 & $30(6 * 5,3)$ & $41: 1$ & 300 \\
\hline $\mathrm{S} 3$ & $\mathrm{MgH}_{2}+\mathrm{TiH}_{2}$ & 95 & 5 & $30(6 * 5,3)$ & $41: 1$ & 300 \\
\hline S4 & $\mathrm{MgH}_{2}+\mathrm{ScCl}_{3}$ & 95 & 5 & $30(6 * 5,3)$ & $41: 1$ & 300 \\
\hline S5 & $\mathrm{MgH}_{2}+\mathrm{VCl}_{3}$ & 95 & 5 & $30(6 * 5,3)$ & $41: 1$ & 300 \\
\hline
\end{tabular}

TABLE I. Composition of the $\mathrm{MgH}_{2}$ + additives samples prepared mechano-chemically. 


\section{RESULTS AND DISCUSSION}

\section{A. Reactions during mechano-chemical and heat treatment}

Dispersion of transition metals in $\mathrm{Mg} / \mathrm{MgH}_{2}$ system is difficult because of the ductility of the metals. Therefore, binary salt-like oxides, chlorides, and hydrides based on early $d$-block metals were selected as additives in the present investigation, i.e., $\mathrm{V}_{2} \mathrm{O}_{5}, \mathrm{VCl}_{3}, \mathrm{ScCl}_{3}, \mathrm{TiH}_{2}$, and $\mathrm{ZrH}_{2}$.

Figures 1-5 show in situ SR-PXD data for the ball-milled samples S1-S5 (see Table I), respectively. Bragg diffraction peaks of $\beta-, \gamma-\mathrm{MgH}_{2}$, and $\mathrm{MgO}$ are observed for sample $\mathrm{S} 1$ (Figure 1) at RT. There is no observed diffraction from $\mathrm{V}_{2} \mathrm{O}_{5}$, which suggests that a redox reaction has occurred during mechano-chemical treatment [see reaction scheme (3)]. Decomposition of $\mathrm{MgH}_{2}$ initiates at $270{ }^{\circ} \mathrm{C}$ by decreasing excess hydrogen pressure below equilibrium at this temperature. All $\gamma-\mathrm{MgH}_{2}$ disappears within $<1 \mathrm{~min}$ of heating at $270{ }^{\circ} \mathrm{C}$ and most of the present $\beta-\mathrm{MgH}_{2}(90 \%)$ is decomposed after 10 min (during measurement of 40 PXD patterns). The PXD data show the presence of $\mathrm{Mg}, \mathrm{MgO}$, and possibly $\mathrm{V}$ at $270{ }^{\circ} \mathrm{C}$. The latter two phases are difficult to distinguish owing to overlapping Bragg reflections.

$$
5 \mathrm{MgH}_{2}+\mathrm{V}_{2} \mathrm{O}_{5} \rightarrow 2 \mathrm{~V}+5 \mathrm{MgO}+5 \mathrm{H}_{2}
$$

PXD patterns of the samples S2 and S3 measured at RT reveal diffracted intensities from the reactants only, i.e., no reaction has occurred between $\mathrm{ZrH}_{2}$ or $\mathrm{TiH}_{2}$ and $\mathrm{MgH}_{2}$. Notice that there is no observed diffraction from $\mathrm{MgO}$ in sample $\mathrm{S} 2$ and $\mathrm{S} 3$. This indicates that the presence of $\mathrm{MgO}$ in $\mathrm{S} 1$ is because of a reaction between $\mathrm{V}_{2} \mathrm{O}_{5}$ and $\mathrm{MgH}_{2}$. Magnesium metal formation in both samples, S2 and S3, initiates at $270{ }^{\circ} \mathrm{C}$ when the pressure is reduced.

The as-milled chloride doped sample $\mathrm{S} 4$ reveals diffraction from $\mathrm{MgH}_{2}$ and scandium(II) hydride $\mathrm{ScH}_{2}$ and no

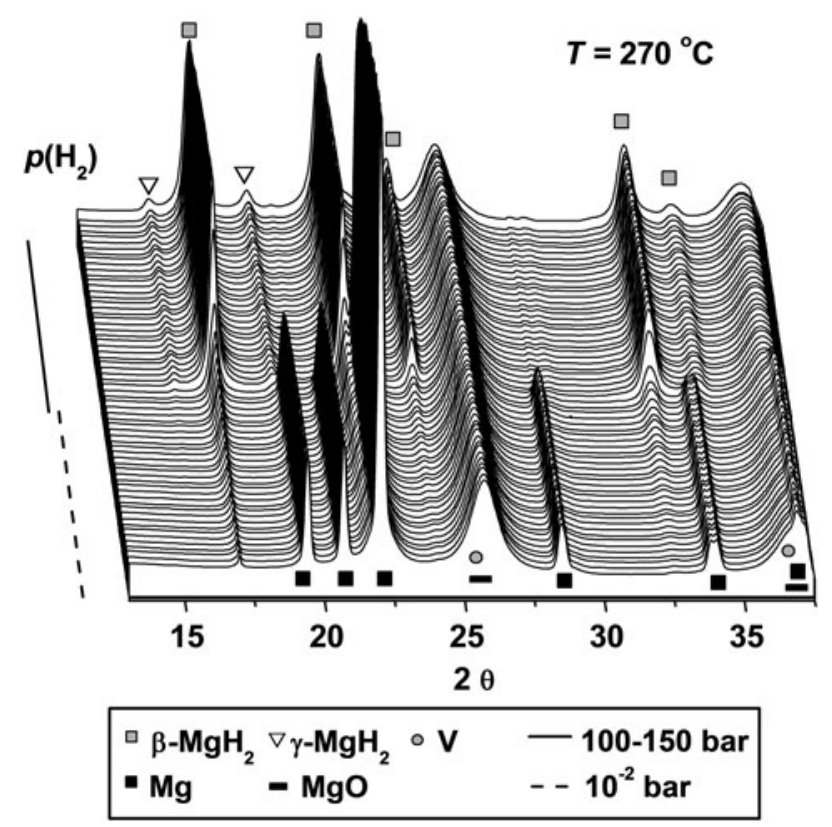

Figure 1. In-situ SR-PXD data measured for sample $\mathrm{MgH}_{2}-\mathrm{V}_{2} \mathrm{O}_{5}$ (S1) heated under $p\left(\mathrm{H}_{2}\right)=100 \mathrm{bar}$ from $\mathrm{RT}$ to $270{ }^{\circ} \mathrm{C}\left(15^{\circ} \mathrm{C} \mathrm{min}{ }^{-1}\right)$ and subsequently dehydrogenated and hydrogenated at this temperature applying alternately $p\left(\mathrm{H}_{2}\right)=10^{-2}$ and $100-150$ bar $(\lambda=0.94608 \AA)$.

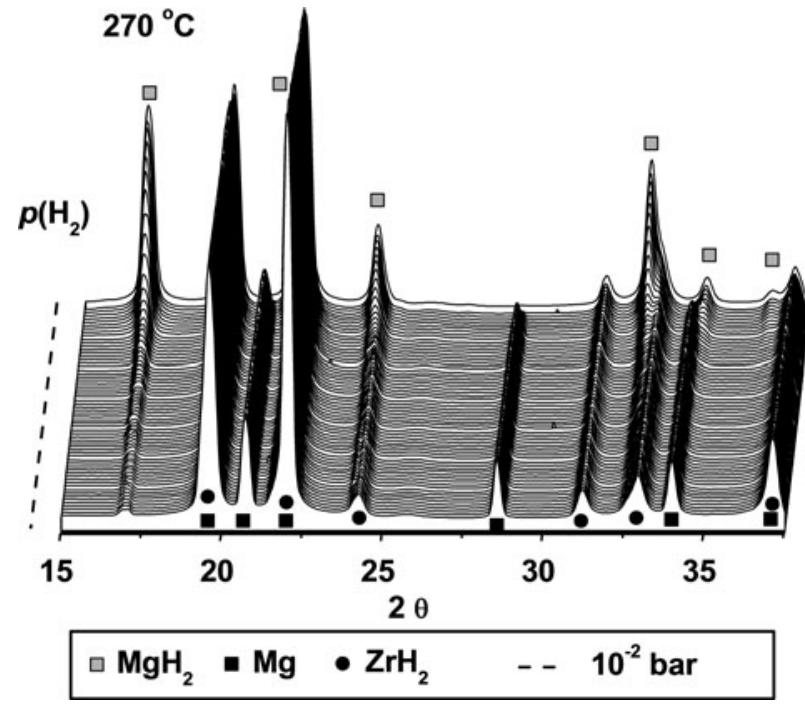

Figure 2. In-situ SR-PXD data measured for sample $\mathrm{MgH}_{2}-\mathrm{ZrH}_{2}$ (S2) heated under $p\left(\mathrm{H}_{2}\right)=100$ bar from RT to $270^{\circ} \mathrm{C}\left(15^{\circ} \mathrm{C} \mathrm{min}{ }^{-1}\right)$ and subsequently dehydrogenated at this temperature applying $p\left(\mathrm{H}_{2}\right)=10^{-2}(\lambda$ $=0.94608 \AA$ ).

diffraction from the additive, $\mathrm{ScCl}_{3}$. This indicates that a redox reaction has occurred during ball-milling [see reaction scheme (4)]. Formation of magnesium initiates when the pressure is reduced at $270{ }^{\circ} \mathrm{C}$. Formation of $\mathrm{MgCl}_{2}$ is observed during the rehydrogenation at $p\left(\mathrm{H}_{2}\right)=100$ bar.

$$
5 \mathrm{MgH}_{2}+\mathrm{ScCl}_{3} \rightarrow \mathrm{MgCl}_{2}+\mathrm{ScH}_{2}+0.5 \mathrm{H}_{2}
$$

Sample S5 $\left(\mathrm{MgH}_{2}-\mathrm{VCl}_{3}\right)$ behaves in a similar way, i.e., no observation of $\mathrm{VCl}_{3}$ after milling, crystallization of $\mathrm{MgCl}_{2}$
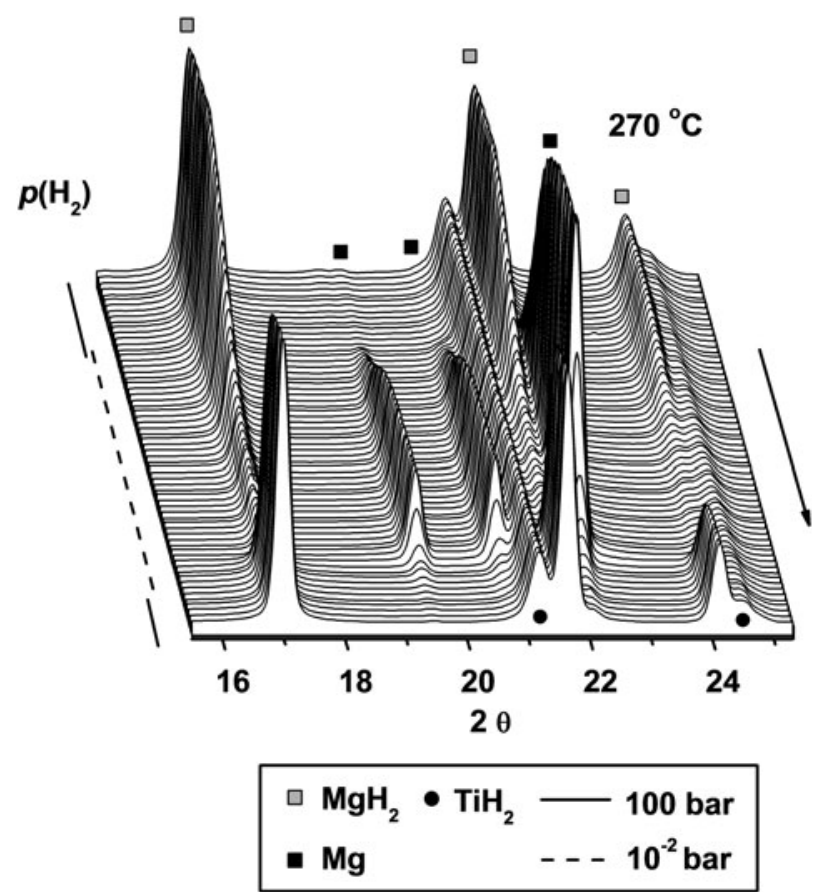

Figure 3. In-situ SR-PXD data measured for sample $\mathrm{MgH}_{2}-\mathrm{TiH}_{2}$ (S3) heated under $p\left(\mathrm{H}_{2}\right)=100$ bar from RT to $270^{\circ} \mathrm{C}\left(15^{\circ} \mathrm{C} \mathrm{min}{ }^{-1}\right)$ and subsequently cycled at this temperature applying alternately $p\left(\mathrm{H}_{2}\right)=10^{-2}$ and $100-150$ bar $(\lambda=0.94608 \AA)$. 


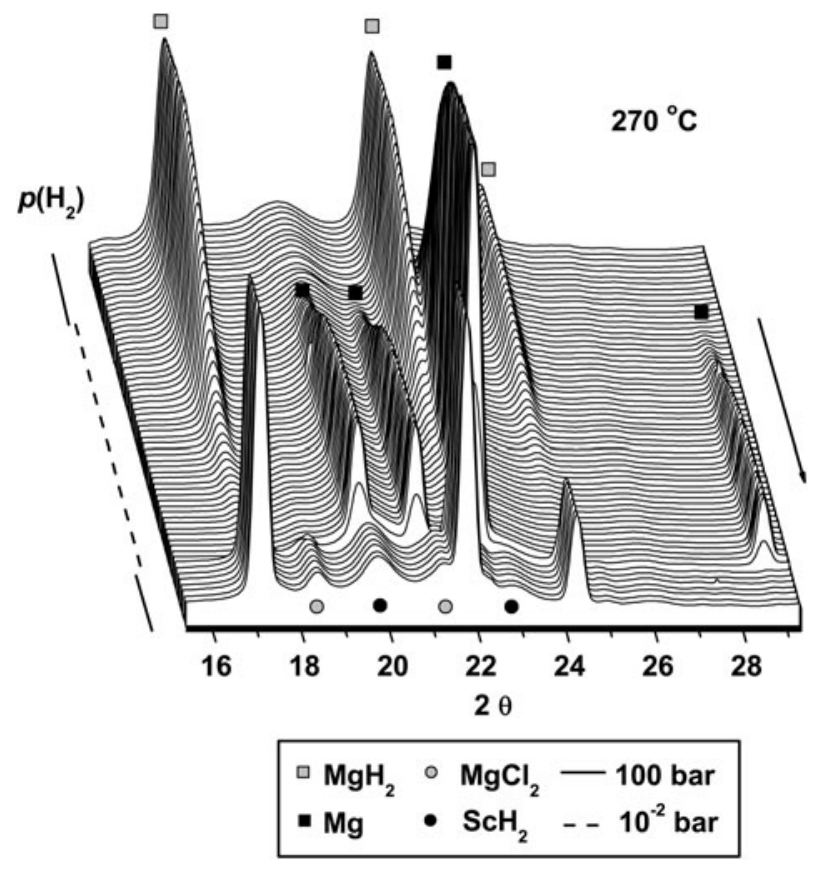

Figure 4. In-situ SR-PXD data measured for sample $\mathrm{MgH}_{2}-\mathrm{ScCl}_{3}$ (S4) heated under $p\left(\mathrm{H}_{2}\right)=100 \mathrm{bar}$ from RT to $270{ }^{\circ} \mathrm{C}\left(15^{\circ} \mathrm{C} \mathrm{min}{ }^{-1}\right)$ and subsequently cycled at this temperature applying alternately $p\left(\mathrm{H}_{2}\right)=10^{-2}$ and $100-150$ bar $(\lambda=0.94608 \AA)$.

during rehydrogenation (see Figure 5). Furthermore, unidentified reflection reveals a continuous change in composition at $2 \theta=24.9-25.4^{\circ}$ under vacuum.

\section{B. Evaluation of additives kinetic effect}

In situ SR-PXD data are used to investigate the effect of selected early $d$-block hydrides, oxides, and chlorides additives on the mechanism of hydrogen release and uptake in magnesium hydride system at $270{ }^{\circ} \mathrm{C}$. The diffracted

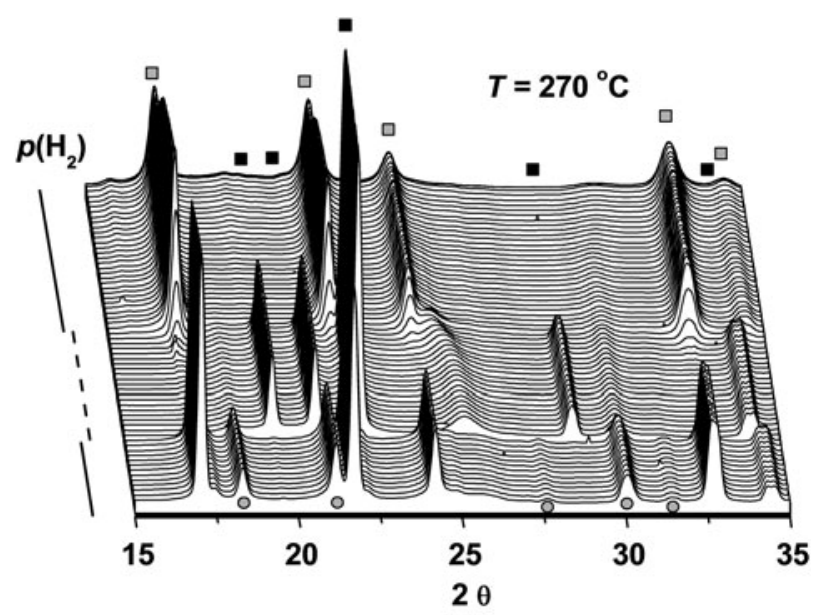

\begin{tabular}{|c|c|c|}
\hline $\begin{array}{l}-\mathrm{MgH}_{2} \\
\circ \mathrm{MgCl}_{2}\end{array}$ & - Mg & $\begin{array}{l}-100 \mathrm{bar} \\
-10^{-2} \mathrm{bar}\end{array}$ \\
\hline
\end{tabular}

Figure 5. In-situ SR-PXD data measured for sample $\mathrm{MgH}_{2}-\mathrm{VCl}_{3}$ (S5) heated under $p\left(\mathrm{H}_{2}\right)=100$ bar from RT to $270{ }^{\circ} \mathrm{C}\left(15^{\circ} \mathrm{C} \mathrm{min}^{-1}\right)$ and subsequently cycled at this temperature applying alternately $p\left(\mathrm{H}_{2}\right)=10^{-2}$ and $100-150$ $\operatorname{bar}(\lambda=0.94608 \AA)$. intensities from $\mathrm{MgH}_{2}$ are integrated, normalized, and converted to phase fraction and used to visualize decreasing amounts of $\mathrm{MgH}_{2}$ during dehydrogenation reactions (Figure 6). At $270{ }^{\circ} \mathrm{C}$ the weakest kinetic effect for hydrogen desorption is provided by $\mathrm{ScCl}_{3}(\mathrm{~S} 4)$ and $\mathrm{TiH}_{2}(\mathrm{~S} 3)$ and the strongest influence is provided by $\mathrm{VCl}_{3}(\mathrm{~S} 5)$ and $\mathrm{V}_{2} \mathrm{O}_{5}(\mathrm{~S} 1)$. In the early stages of $\mathrm{MgH}_{2}$ decomposition $\mathrm{V}_{2} \mathrm{O}_{5}$ demonstrates the fastest kinetics, which is somewhat slowed down in the late stage of the decomposition. In contrast, the effect from $\mathrm{VCl}_{3}$ additive is also significant in the late stage of the decomposition. Zirconium hydride (S2) has an intermediate kinetic effect. A similar analysis of additives effect was also performed at higher temperature of $320^{\circ} \mathrm{C}$ and the results are presented in Figure 7. The time scale for these experiments is clearly shorter as compared with those performed at $270{ }^{\circ} \mathrm{C}$. In addition, the additives ability to accelerate the reaction kinetics follows the sequence: $\mathrm{ScCl}_{3}<\mathrm{TiH}_{2}<\mathrm{ZrH}_{2}<\mathrm{VCl}_{3}<\mathrm{V}_{2} \mathrm{O}_{5}$. These experiments reveal that the effect of increasing temperatures on the acceleration of reaction rate is more pronounced

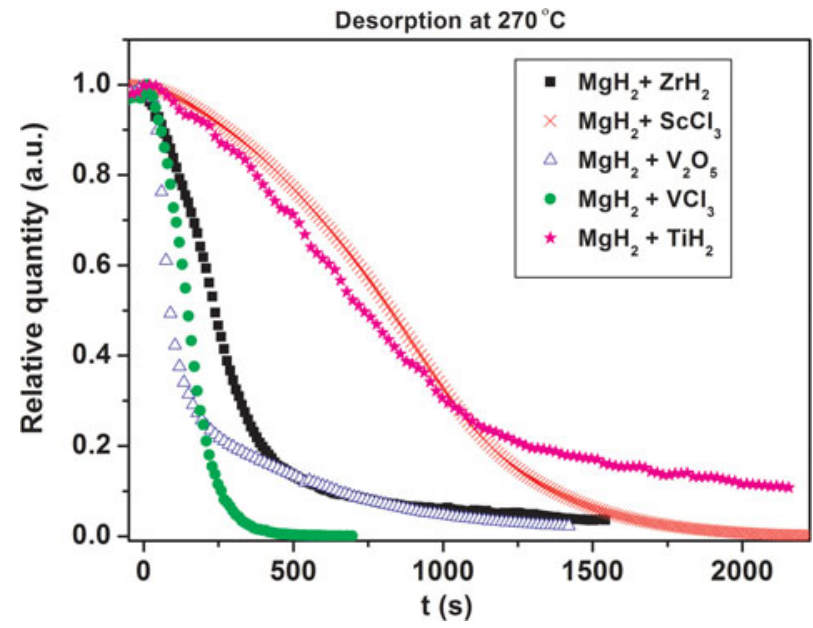

Figure 6. (color online) Integrated normalized diffracted intensities for samples S1-S5 showing changes in the relative amount of $\mathrm{MgH}_{2}$ at $270{ }^{\circ} \mathrm{C}$ as a function of time.

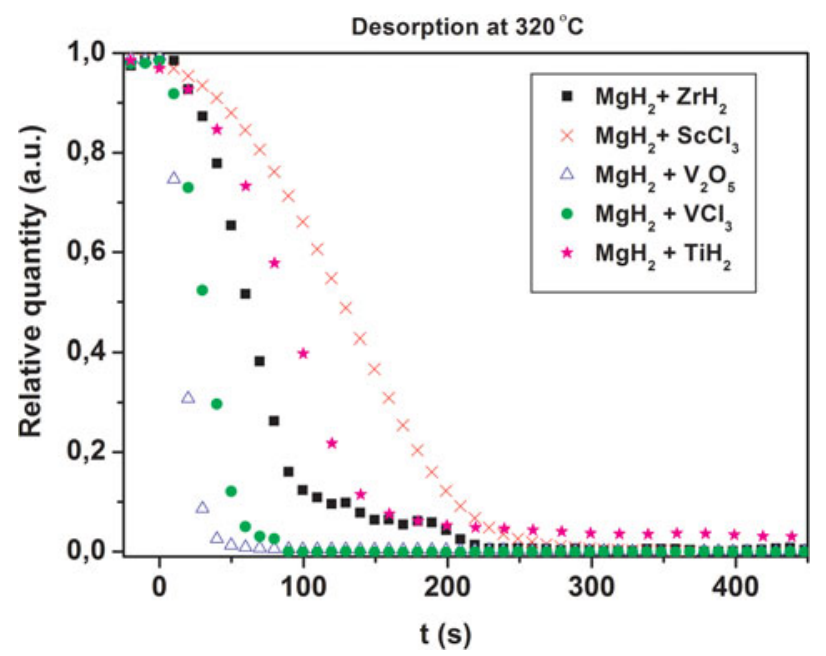

Figure 7. (color online) Integrated normalized diffracted intensities for samples S1-S5 showing changes in the relative amount of $\mathrm{MgH}_{2}$ at $320^{\circ} \mathrm{C}$ as a function of time. 
than the different additives effect. It should be emphasized that commercial $\mathrm{MgH}_{2}$ ball-milled without additives in the same conditions does not desorb hydrogen at 270 nor at $320{ }^{\circ} \mathrm{C}$. Slight yield of hydrogen begins to be observed only at temperatures above $350{ }^{\circ} \mathrm{C}$.

\section{Activation of magnesium hydride via a chemical reaction}

Analysis of the additives effect (Section B) revealed that the best results were obtained using the addition of $\mathrm{V}_{2} \mathrm{O}_{5}$. Here we further analyse the mechanism for this effect. Bragg diffraction peaks of $\beta-, \gamma-\mathrm{MgH}_{2}$ and $\mathrm{MgO}$ are observed for $\mathrm{MgH}_{2}-\mathrm{V}_{2} \mathrm{O}_{5}$ (S1) (see Figure 1), at RT. There is no observed diffraction from $\mathrm{V}_{2} \mathrm{O}_{5}$, which suggest that a redox reaction has occurred during mechano-chemical treatment [see reaction scheme (3)]. To crystallize possible reaction products the same sample was heated to $450{ }^{\circ} \mathrm{C}$ and 2 cycles of hydrogen release and uptake were conducted (see Figure 8). Diffraction peaks from $\mathrm{V}_{2} \mathrm{H}$ are clearly observed at $2 \theta=24.5^{\circ}$ and $35.9^{\circ}$ in the hydrogenated state when the temperature reaches $450{ }^{\circ} \mathrm{C}$ and for $\mathrm{V}$ in the dehydrogenated state at $2 \theta=25.4^{\circ}$ and $36.4^{\circ}$. This leads to the splitting of the peak previously assigned to $\mathrm{MgO}$ and $\mathrm{V}$, at $2 \theta \approx 26^{\circ}$ in Figure 1 . Apparently, the heating procedure fully reduced the possibly remaining $\mathrm{V}_{2} \mathrm{O}_{5}$ and facilitated crystallization of $\mathrm{V}_{2} \mathrm{H} / \mathrm{V}$. The experiment was continued using the same sample (see Figure 9), the temperature was decreased to $270{ }^{\circ} \mathrm{C}$ and one dehydrogenation was conducted similar to what is shown in Figure 1. Presence of vanadium and vanadium hydride is more clearly observed in Figure 9 as compared with Figure 8 and during dehydrogenation diffraction peaks from $\mathrm{V}_{2} \mathrm{H}$ (at $2 \theta=24.4^{\circ}$ ) continuously change position to $2 \theta=$ $25.5^{\circ}$ because of the release of hydrogen and formation of $\mathrm{V}$.

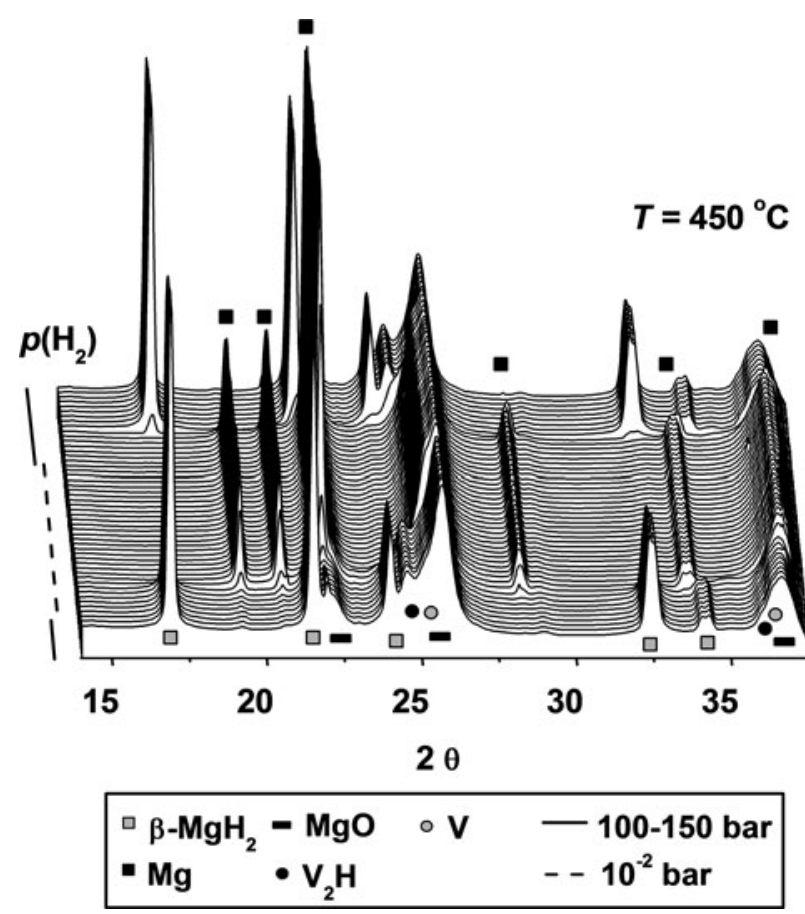

Figure 8. In-situ SR-PXD data of the activation process for sample $\mathrm{MgH}_{2}-$ $\mathrm{V}_{2} \mathrm{O}_{5}(\mathrm{~S} 1)$ heated under $p\left(\mathrm{H}_{2}\right)=100$ bar from 320 to $450{ }^{\circ} \mathrm{C}\left(15^{\circ} \mathrm{C} \mathrm{min}^{-1}\right)$ and subsequently cycled at this temperature applying alternately $p\left(\mathrm{H}_{2}\right)=$ $10^{-2}$ and $100-150 \operatorname{bar}(\lambda=0.94608 \AA)$.
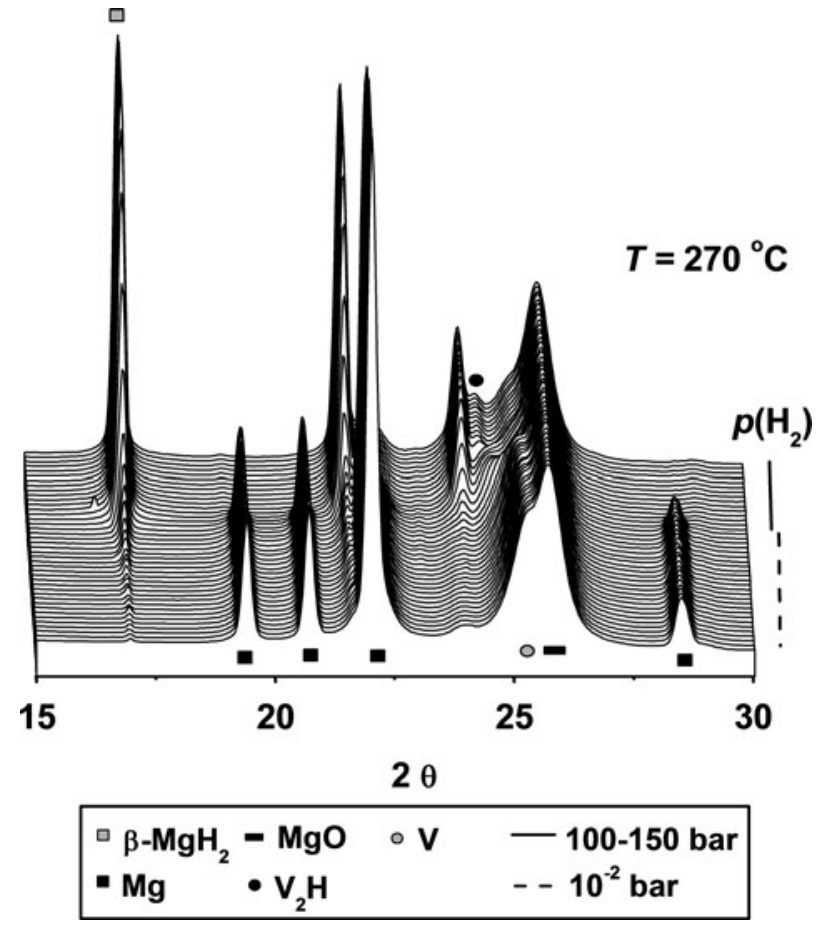

Figure 9. In-situ SR-PXD data of post-activation desorption measured for sample $\mathrm{MgH}_{2}-\mathrm{V}_{2} \mathrm{O}_{5}(\mathrm{~S} 1)$ cooled from 450 to $270{ }^{\circ} \mathrm{C}$ under $p\left(\mathrm{H}_{2}\right)=100$ bar $\left(15^{\circ} \mathrm{C} \mathrm{min}^{-1}\right)$ where the pressure was decreased to $p\left(\mathrm{H}_{2}\right)=10^{-2} \mathrm{bar}$ $(\lambda=0.94608 \AA)$.

The activation procedure, i.e., cycling at $450{ }^{\circ} \mathrm{C}$ clearly improves the desorption kinetics. This is illustrated in Figure 10 where extracted decomposition curves for $\mathrm{MgH}_{2}$ are shown using data from Figures 1 and 9. After the activation process (Figure 8) the release of hydrogen from $\mathrm{MgH}_{2}$ is both faster and more complete. This may be related to the formation of more $\mathrm{V}_{2} \mathrm{H} / \mathrm{V}$ in the sample and the fact that the hydrogen permeability of vanadium is large and exceeds that of palladium (Dolan, 2010). It is known that $\mathrm{Nb}$ and $\mathrm{V}$ based alloys are promising membranes materials, which currently are developed instead of Pd based alloys (Yukawa et al., 2012). Therefore, the $\mathrm{V}_{2} \mathrm{H} / \mathrm{V}$ system may be the active catalytic component for the $\mathrm{MgH}_{2}-\mathrm{V}_{2} \mathrm{O}_{5}$ system.

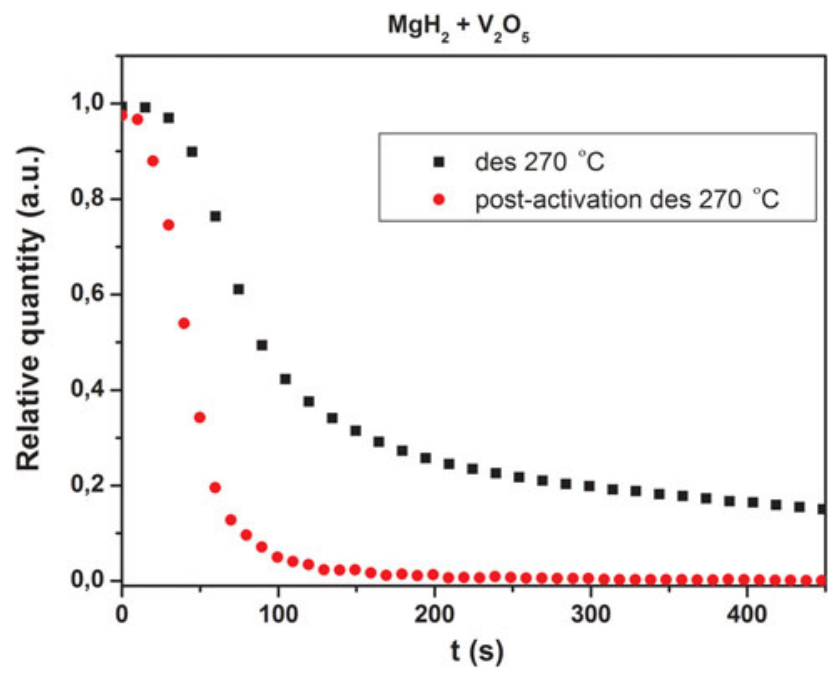

Figure 10. (color online) Comparison of the kinetic curves for $\mathrm{MgH}_{2}$ decomposition at $270{ }^{\circ} \mathrm{C}$ before and after the activation of $\mathrm{MgH}_{2}-\mathrm{V}_{2} \mathrm{O}_{5}(\mathrm{~S} 1)$. 


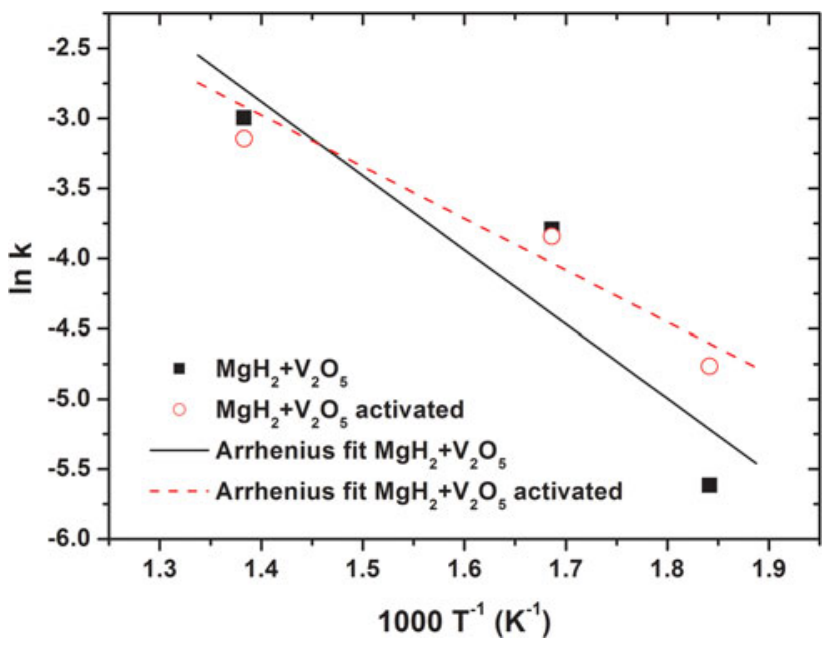

Figure 11. (color online) Arrhenius plot of the kinetic data for dehydrogenation of $\mathrm{MgH}_{2}-\mathrm{V}_{2} \mathrm{O}_{5}(\mathrm{~S} 1)$.

\section{Apparent activation energy for the $\mathrm{MgH}_{2}$ decomposition}

The decomposition curves for $\mathrm{MgH}_{2}-\mathrm{V}_{2} \mathrm{O}_{5}(\mathrm{~S} 1)$ can be fitted well using the contracting surface model (two-dimensional growth) (Bamford and Tipper, 1980), e.g., kinetic shrinking core model, which suggests that hydrogen desorption is interface controlled (Liang et al., 2000; Varin et al., 2009).

An Arrhenius plot of the natural logarithm to the rate constant as a function of inverse temperature is provided in Figure 11 . The calculated apparent activation energy $E_{\mathrm{A}}=$ $43 \mathrm{~kJ} \mathrm{~mol}^{-1}$ is obtained for the $\mathrm{MgH}_{2}-\mathrm{V}_{2} \mathrm{O}_{5}$ sample $\mathrm{S} 1$ after milling. This value compares well to the activation energy for long range hydrogen diffusion in bulk $\mathrm{Mg}$ determined from experimental data to be $E_{\mathrm{A}}=40.2 \mathrm{~kJ} \mathrm{~mol}^{-1}$ (Renner and Grabke, 1978). For the fully activated sample S1 the compounds $\mathrm{V} / \mathrm{V}_{2} \mathrm{H}$ are identified to be the active catalytic compounds, which facilitate hydrogen release. The in situ SR-PXD data also allow to extract an apparent activation energy for the activated sample, $E_{\mathrm{A}}=34 \mathrm{~kJ} \mathrm{~mol}^{-1}$ (see Figure 11). These measured values are low, in particular when compared with that for bulk (unmilled) and air-exposed $\mathrm{MgH}_{2}, E_{\mathrm{A}}=300 \mathrm{~kJ} \mathrm{~mol}^{-1}$ (Jensen et al., 2006). Apparent activation energies of $E_{\mathrm{A}}=52$ and $120 \mathrm{~kJ} \mathrm{~mol}^{-1}$ are measured for mechano-chemically treated $\mathrm{MgH}_{2}$ with and without vanadium (5 mol\%) as additive (Liang et al., 1999b, 2000).

Thus, this kinetic analysis reveals that in situ synthesis of small particles of $\mathrm{V} / \mathrm{V}_{2} \mathrm{H}$ in the sample during cycling appears to have a stronger catalytic effect on hydrogen release and uptake in magnesium/magnesium hydride system. This may be because of a more uniform distribution of catalytic active particles compared with mechano-chemically prepared samples of $\mathrm{MgH}_{2}-\mathrm{V}$. There are inherent difficulties with obtaining uniform distribution of ductile metals in $\mathrm{MgH}_{2}$ in contrast to brittle oxides that tend to form more homogenous distributed samples. The drawback is that considerable amounts of inert $\mathrm{MgO}$ are formed during reduction of $\mathrm{V}_{2} \mathrm{O}_{5}$ in the $\mathrm{MgH}_{2}-\mathrm{V}_{2} \mathrm{O}_{5}$ system.

\section{E. On the catalytic properties of vanadium pentoxide and vanadium metal}

There are several studies that report high catalytic activity of $\mathrm{V}_{2} \mathrm{O}_{5}$ for release and uptake in magnesium hydride
(Oelerich et al., 2001a, 2001b; Barkhordarian et al., 2006; Jung et al., 2006). Vanadium(V) oxide, similar to niobium (V) oxide, is readily reduced in contact with hydrogen or mechano-chemically treated with $\mathrm{MgH}_{2}$ (Jung et al., 2006; Nielsen and Jensen, 2012). Several lower oxides may act as intermediates during the formation of $\mathrm{MgO}$. The final product is shown here to be vanadium, which also participate in hydrogen release and uptake via $\mathrm{V} / \mathrm{V}_{2} \mathrm{H}$ system.

As mentioned above vanadium does not form alloy or intermetallic compounds with $\mathrm{Mg}$ (Schimmel et al., 2005) thus it can act as a pure catalyst. $\mathrm{MgH}_{2}-5 \mathrm{~mol} \% \mathrm{~V}$ composite desorbs hydrogen at $473 \mathrm{~K}$ (under vacuum) and re-absorbs hydrogen rapidly even at RT (Liang et al., 1999b). The desorption rate was the highest for this mixture and decreased in the following order of additives: Ti, Mn, Fe, and Ni (Liang et al., 1999a).

Moreover, $\mathrm{MgH}_{2}-5 \mathrm{~mol} \% \mathrm{~V}$ system has the fastest kinetics for hydrogen release and uptake in magnesium hydride in comparison with $\mathrm{Ti}$ and is similar to $\mathrm{Nb}$ additive (Charbonnier et al., 2004). Mg-10 wt.\%V system exhibits the highest rate of hydrogen desorption and shows the lowest activation energy among $\mathrm{Y}$ and $\mathrm{Zr}$ additives (Czujko et al., 2006). In addition, vanadium itself reversibly absorbs and desorbs $2.3 \mathrm{wt} \%$ of hydrogen at RT, which is also larger than that of the known alloys, $\mathrm{LaNi}_{5}, \mathrm{FeTi}$ (Varin et al., 2009; Nakamura et al., 2012).

\section{CONCLUSION}

Using the same conditions for the synthesis (mechanochemical treatment) and evaluation of properties (hydrogenvacuum cycling) a comparative analysis was carried out and the best from the studied catalysts for desorption/absorption of hydrogen for commercial powder $\mathrm{MgH}_{2}$ was determined. It was found that the fastest kinetics at $320^{\circ} \mathrm{C}$ shows the sample with additive of $5 \mathrm{~mol} \% \mathrm{~V}_{2} \mathrm{O}_{5}$. Additional activation of the system $\left(2\right.$ cycles at $450{ }^{\circ} \mathrm{C}$ ) leads to the significant improvement and acceleration of kinetics even at lower $270{ }^{\circ} \mathrm{C}$ temperature. Observed effect is achieved through the full reduction of vanadium oxides, the formation of new efficient catalyst in the form of ultrafine particles of vanadium and purification of interface $\mathrm{MgH}_{2} / \mathrm{V}$ in the process of heating to $450{ }^{\circ} \mathrm{C}$ in dynamic vacuum. This reduces the apparent activation energy of hydrogen desorption below the values of the activation energy of hydrogen diffusion in $\mathrm{Mg}$, owing to the joint effect of nanostructuring and high hydrogen permeability of vanadium catalyst, which strongly bound to the surface of the $\mathrm{MgH}_{2}$ crystallites. Thus the real catalyst for the hydrogen release/uptake in the $\mathrm{MgH}_{2}$ is nanoparticles of pure vanadium obtained by the full reduction of $\mathrm{V}_{2} \mathrm{O}_{5}$ that was used originally.

\section{ACKNOWLEDGEMENTS}

The authors acknowledge funding for this research from the Danish Research Council for Natural Sciences (Danscatt). Moreover, the work was supported by the Danish National Research Foundation (Centre for Materials Crystallography), the Danish Strategic Research Council (Centre for Energy Materials), and the Carlsberg Foundation and the Swedish Research Council. The access to beam time at the MAX II synchrotron, Lund, Sweden in the research laboratory MAX-lab is gratefully acknowledged. Support from EU COST action MP1103 is also acknowledged. 
Andreasen, A., Sorensen, M. B., Burkarl, R., Moller, B., Molenbroek, A. M., Pedersen, A. S., Andreasen, J. W., Nielsen, M. M., and Jensen, T. R. (2005). "Interaction of hydrogen with an Mg-Al alloy," J. Alloys Compd. 404, 323-326.

Andreasen, A., Sørensen, M. B., Burkarl, R., Møller, B., Molenbroek, A. M., Pedersen, A. S., Vegge, T., and Jensen, T. R. (2006). "Dehydrogenation kinetics of air-exposed $\mathrm{MgH}_{2} / \mathrm{Mg}_{2} \mathrm{Cu}$ and $\mathrm{MgH}_{2} / \mathrm{MgCu}_{2}$ studied with in situ X-ray powder diffraction," Appl. Phys. A Mater 82, 515-521.

Bamford, C. H. and Tipper, C. F. H. (1980). "Theory of solid state reaction kinetics," in Comprehensive Chemical Kinetics, Brown, M. E., Dollimore, D., and Galwey, A. K., eds. (Elsevier, Amsterdam, Netherlands), Vol. 22, pp. 41-113.

Barkhordarian, G., Klassen, T., and Bormann, R. (2006). "Catalytic mechanism of transition-metal compounds on $\mathrm{Mg}$ hydrogen sorption reaction," J. Phys. Chem. B 110, 11020-11024.

Bhat, V. V., Rougier, A., Aymard, L., Darok, X., Nazri, G., and Tarascon, J. M. (2006). "Catalytic activity of oxides and halides on hydrogen storage of $\mathrm{MgH}_{2}$," J. Power Sources 159, 107-110.

Callini, E., Pasquini, L., Rude, L. H., Nielsen, T. K., Jensen, T. R., and Bonetti, E. (2010). "Hydrogen storage and phase transformations in Mg-Pd nanoparticles,” J. Appl. Phys. 108, 073513.

Callini, E., Pasquini, L., Jensen, T. R., and Bonetti, E. (2013). "Hydrogen storage properties of Mg-Ni nanoparticles," Int. J. Hydrog. Energy 38, 1220712212.

Charbonnier, J., de Rango, P., Fruchart, D., Miraglia, S., Pontonnier, L., Rivoirard, S., Skryabina, N., and Vulliet, P. (2004). "Hydrogenation of transition element additives ( $\mathrm{Ti}, \mathrm{V}$ ) during ball milling of magnesium hydride," J. Alloys Compd. 383, 205-208.

Cuevas, F., Korablov, D., and Latroche, M. (2012). "Synthesis, structural and hydrogenation properties of $\mathrm{Mg}$-rich $\mathrm{MgH}_{2}-\mathrm{TiH}_{2}$ nanocomposites prepared by reactive ball milling under hydrogen gas," Phys. Chem. Chem. Phys. 14, 1200-1211.

Czujko, T., Varin, R. A., Chiu, C., and Wronski, Z. (2006). "Investigation of the hydrogen desorption properties of $\mathrm{Mg}+10 \mathrm{wt} \% \mathrm{X}(\mathrm{X}=\mathrm{V}, \mathrm{Y}, \mathrm{Zr})$ submicrocrystalline composites," J. Alloys Compd. 414, 240-247.

Deledda, S., Borissova, A., Poinsignon, C., Botta, W. J., Dornheim, M., and Klassen, T. (2005). "H-sorption in $\mathrm{MgH}_{2}$ nanocomposites containing $\mathrm{Fe}$ or Ni with fluorine,” J. Alloys Compd. 404-406, 409-412.

Dolan, M. D. (2010). "Non-Pd BCC alloy membranes for industrial hydrogen separation,” J. Membr. Sci. 362, 12-28.

Hammersley, A. P., Svensson, S. O., Hanfland, M., Fitch, A. N., and Hausermann, D. (1996). "Two-dimensional detector software: from real detector to idealised image or two-theta scan," High Press. Res. 14, 235-248.

Hirokazu, K. and Kitagawa, H. (2012). "Nanostructured materials for hydrogen storage," Int. Symp. on Metal-Hydrogen Systems, Kyoto, Japan, p. 187.

Huot, J., Liang, G., Boily, S., Van Neste, A., and Schulz, R. (1999). "Structural study and hydrogen sorption kinetics of ball-milled magnesium hydride," J. Alloys Compd. 293, 495-500.

Huot, J., Ravnsbæk, D. B., Zhang, J., Cuevas, F., Latroche, M., and Jensen, T. R. (2013). "Mechanochemical synthesis of hydrogen storage materials," Progr. Mater. Sci. 58, 30-75.

Ivanov, E., Konstanchuk, I., Bokhonov, B., and Boldyrev, V. (2003). "Hydrogen interaction with mechanically alloyed magnesium-salt composite materials," J. Alloys Compd. 359, 320-325.

Jensen, T. R., Andreasen, A., Vegge, T., Andreasen, J. W., Stahl, K., Pedersen, A. S., Nielsen, M. M., Molenbroek, A. M., and Besenbacher, F. (2006). "Dehydrogenation kinetics of pure and nickel-doped magnesium hydride investigated by in situ time-resolved powder X-ray diffraction," Int. J. Hydrog. Energy 31, 2052-2062.

Jensen, T. R., Nielsen, T. K., Filinchuk, Y., Jorgensen, J. E., Cerenius, Y., Gray, E. M., and Webb, C. J. (2010). "Versatile in situ powder X-ray diffraction cells for solid-gas investigations," J. Appl. Crystallogr. 43, 1456-1463.

Jin, S.-A., Shim, J.-H., Ahn, J.-P., Cho, Y. W., and Yi, K.-W. (2007a). "Improvement in hydrogen sorption kinetics of $\mathrm{MgH}_{2}$ with $\mathrm{Nb}$ hydride catalyst," Acta Mater. 55, 5073-5079.

Jin, S. A., Shim, J. H., Cho, Y. W., and Yi, K. W. (2007b). "Dehydrogenation and hydrogenation characteristics of $\mathrm{MgH}_{2}$ with transition metal fluorides," J. Power Sources 172, 859-862.
Jung, K. S., Lee, E. Y., and Lee, K. S. (2006). “Catalytic effects of metal oxide on hydrogen absorption of magnesium metal hydride," J. Alloys Compd. 421, 179-184.

Kim, J. W., Ahn, J. P., Jin, S. A., Lee, S. H., Chung, H. S., Shim, J. H., Cho, Y. W., and $\mathrm{Oh}, \mathrm{K} . \mathrm{H}$. (2008). "Microstructural evolution of $\mathrm{NbF}_{5}$-doped $\mathrm{MgH}_{2}$ exhibiting fast hydrogen sorption kinetics," J. Power Sources 178, 373-378.

Liang, G., Huot, J., Boily, S., Van Neste, A., and Schulz, R. (1999a). "Catalytic effect of transition metals on hydrogen sorption in nanocrystalline ball milled $\mathrm{MgH}_{2}-\mathrm{Tm}(\mathrm{Tm}=\mathrm{Ti}, \mathrm{V}, \mathrm{Mn}, \mathrm{Fe}$ and $\mathrm{Ni}$ ) systems," J. Alloys Compd. 292, 247-252.

Liang, G., Huot, J., Boily, S., Van Neste, A., and Schulz, R. (1999b). "Hydrogen storage properties of the mechanically milled $\mathrm{MgH}_{2}-\mathrm{V}$ nanocomposite," J. Alloys Compd. 291, 295-299.

Liang, G., Huot, J., Boily, S., and Schulz, R. (2000). "Hydrogen desorption kinetics of a mechanically milled $\mathrm{MgH}_{2}+5$ at. $\% \mathrm{~V}$ nanocomposite," J. Alloys Compd. 305, 239-245.

Ma, L. P., Kang, X. D., Dai, H. B., Liang, Y., Fang, Z. Z., Wang, P. J., Wang, P., and Cheng, H. M. (2009). "Superior catalytic effect of $\mathrm{TiF}_{3}$ over $\mathrm{TiCl}_{3}$ in improving the hydrogen sorption kinetics of $\mathrm{MgH}_{2}$ : catalytic role of fluorine anion," Acta Mater. 57, 2250-2258

Malka, I. E., Czujko, T., and Bystrzycki, J. (2010). "Catalytic effect of halide additives ball milled with magnesium hydride,’ Int. J. Hydrog. Energy 35, 1706-1712.

Massalski, T. B. (1990). Binary Alloy Phase Diagrams (ASM International, Materials Park, OH, USA)

Nakamura, J., Kato, N., Takamatsu, Y., Fuura, T., Oosawa, M., and Tsunokake, S. (2012). "Hydrogen storage properties of the Ti-V-Cr-Fe alloy used vanadium obtained by thermite reaction," Int. Symp. on Metal-Hydrogen Systems, Kyoto, Japan, p. 121.

Nielsen, T. K. and Jensen, T. R. (2012). " $\mathrm{MgH}_{2}-\mathrm{Nb}_{2} \mathrm{O}_{5}$ investigated by in situ synchrotron X-ray diffraction,” Int. J. Hydrog. Energy 37, 13409-13416.

Nielsen, T. K., Manickam, K., Hirscher, M., Besenbacher, F., and Jensen, T. R. (2009). "Confinement of $\mathrm{MgH}_{2}$ nanoclusters within nanoporous aerogel scaffold materials," ACS Nano 3, 3521-3528.

Nielsen, T. K., Besenbacher, F., and Jensen, T. R. (2011). "Nanoconfined hydrides for energy storage," Nanoscale 3, 2086-2098.

Oelerich, W., Klassen, T., and Bormann, R. (2001a). "Comparison of the catalytic effects of $\mathrm{V}, \mathrm{V}_{2} \mathrm{O}_{5}, \mathrm{VN}$, and $\mathrm{VC}$ on the hydrogen sorption of nanocrystalline Mg," J. Alloys Compd. 322, L5-L9.

Oelerich, W., Klassen, T., and Bormann, R. (2001b). "Metal oxides as catalysts for improved hydrogen sorption in nanocrystalline Mg-based materials," J. Alloys Compd. 315, 237-242.

Paskevicius, M., Sheppard, D. A., and Buckley, C. E. (2010). "Thermodynamic changes in mechanochemically synthesized magnesium hydride nanoparticles," J. Am. Chem. Soc. 132, 5077-5083.

Pasquini, L., Callini, E., Brighi, M., Boscherini, F., Montone, A., Jensen, T. R., Maurizio, C., Antisari, M. V., and Bonetti, E. (2011). "Magnesium nanoparticles with transition metal decoration for hydrogen storage," J. Nanopart. Res. 13, 5727-5737.

Renner, J. and Grabke, H. J. (1978). "Determination of diffusion coefficients in the hydriding of alloys," Mater. Res. Adv. Tech. 69, 639-642.

Rodríguez-Carvajal, J. (1993). "Recent advances in magnetic structure determination by neutron powder diffraction," Physica B 192, 55-69.

Sato, M. and Ishikawa, S. (2012). "Reversible multi step hydrogen absorption and desorption by $\mathrm{Mg}_{12} \mathrm{Zn}_{13}$," Int. Symp. on Metal-Hydrogen Systems, Kyoto, Japan, p. 100

Schimmel, H. G., Huot, J., Chapon, L. C., Tichelaar, F. D., and Mulder, F. M. (2005). "Hydrogen cycling of niobium and vanadium catalyzed nanostructured magnesium," J. Am. Chem. Soc. 127, 14348-14354.

Vajo, J. J. (2011). "Influence of nano-confinement on the thermodynamics and dehydrogenation kinetics of metal hydrides," Curr. Opin. Solid State Mater. Sci. 15, 52-61.

Varin, R. A., Czujko, T. and Wronski, Z. S. (2009). Nanomaterials for Solid State Hydrogen Storage (Springer, New York).

Varin, R. A., Zbroniec, L., Polanski, M., and Bystrzycki, J. (2011). "A review of recent advances on the effects of microstructural refinement and nanocatalytic additives on the hydrogen storage properties of metal and complex hydrides," Energies 4, 1-25.

Yukawa, H., Nambu, T., and Matsumoto, Y. (2012). "Hydrogen solubility and permeability of V-W-Mo alloy membrane for hydrogen separation and purification," Int. Symp. on Metal-Hydrogen Systems, Kyoto, Japan, p. 426. 